\title{
O TRABALHO E A ORIGEM DO HOMEM EM SOCIEDADE: UMA ANÁLISE ATRAVÉS DA FILOSOFIA DE MARX E LUKÁCS
}

\author{
Ângelo Antônio Macêdo Leite ${ }^{1}$
}

\section{CONSIDERAÇÕES INICIAIS}

Na perspectiva lukácsiana, o trabalho é considerado a categoria fundante do ser social. É pelo trabalho que os homens se relacionam entre si. Sem trabalho não há sociedade, pois é através dele que a relações iniciais são construídas.

O trabalho tem sido essencial para a evolução do ser humano. Através das mudanças tecnológicas é possível verificar uma adaptação do homem sobre alguns desafios da natureza. $\mathrm{O}$ trabalho tem ajudado o homem a ampliar suas habilidades e melhorar o bem estar de uma sociedade. O trabalho está na base da atividade econômica e social de uma sociedade. $\mathrm{Na}$ sociedade capitalista atual, por exemplo, é com o trabalho que se criam as mercadorias que constituem a riqueza de uma sociedade.

Discutir sobre o papel do trabalho no interior de uma sociedade é fundamental para o entendimento do ser humano e de suas relações sociais. O objetivo de artigo é debater em uma perspectiva marxista o conceito de trabalho e sua característica fundante do ser social. Para isso, será utilizado especialmente como metodologia uma análise teórica deste tema no livro "O Capital" de Karl Marx.

\section{TRABALHO: RELAÇÃO DO HOMEM COM A NATUREZA}

Para alguns filósofos, como Karl Marx (1818 - 1883), Friedrich Engels (1820 - 1895) e Georg Lukács (1885 - 1971), o trabalho surge por uma necessidade humana de transformar a natureza e dela retirar o seu sustento ou os meios que auxiliaram na realização de tarefas ou de algum lazer. Diante de uma necessidade, o homem se utiliza do trabalho para transformar as matérias naturais em produtos que atendem às suas necessidades.

O trabalho é essencial tanto para a vivência em sociedade, quanto para a sobrevivência do próprio homem enquanto ser biológico, ou como nos diz Engels:

\footnotetext{
${ }^{1}$ Graduando em Filosofia pela CEAD UFPI, macedoleite@hotmail.com
} 
O trabalho é a fonte de toda a riqueza, afirmam os economistas. Assim é, com efeito, ao lado da natureza, encarregada de fornecer muitíssimo mais do que isso. É a condição básica e fundamental de toda a vida humana. E em tal grau que, até certo ponto, podemos afirmar que o trabalho criou o próprio homem. (ENGELS, 2004, p.11).

Para Lukács (1981) o trabalho é a categoria fundante do ser social. Ela é a categoria que dá origem ao agir humano. Sem ele, as inúmeras e variadas formas de atividade humana não poderiam existir. Ele é fundante, pois é a única categoria social que faz a mediação entre o homem e a natureza, gerando novas possibilidades e necessidades.

Somente o trabalho tem, como sua essência ontológica, um claro caráter intermediário: ele é, essencialmente, uma inter-relação entre homem (sociedade) e natureza, tanto inorgânica (utensílio, matéria-prima, objeto do trabalho, etc.) como orgânica, inter-relação que pode até estar situada em pontos determinados da série a que nos referimos, mas antes de mais nada assinala a passagem, no homem que trabalha, do ser meramente biológico ao ser social. (LUKÁCS, 1981, p. 02).

Nesta mesma linha de raciocínio, Marx (2010) afirma que é essencialmente por meio do trabalho que os indivíduos, homens e mulheres, distinguem-se dos outros animais biológicos. $\mathrm{Ou}$ seja, para Marx, o trabalho é uma relação exclusiva entre o homem e a Natureza. "um processo de que participam o homem e a natureza, processo em que o ser humano com sua própria ação impulsiona, regula e controla seu intercâmbio material com a natureza”. (MARX, 2010, p. 211)

Como o ser humano interage com a natureza para produzir os meios de produção ou de subsistência? Para Marx (2010) isto se dá através dos meios de produção, onde o trabalhador os coloca entre ele e o objeto de trabalho. "Ele utiliza as propriedades mecânicas, físicas, químicas das coisas para fazê-las atuarem como forças sobre outras coisas, de acordo com o fim que tem em mira” (MARX, 2010, p. 213).

Os meios de trabalho são usados pelo ser humano para interagir com a natureza. Embora alguns animais utilizem algumas ferramentas para realizar algo, foi somente a espécie humana que se valeu de sua inteligência e conseguiu aprimorar os meios de trabalho, dando início ao processo de desenvolvimento que culminaram na revolução industrial. Foi através das melhorias dos meios de trabalho que a humanidade vivenciou diferentes modos de produção e de vida.

O que distingue as diferentes épocas econômicas não é o que se faz, mas como, com que meios de trabalho se faz. Os meios de trabalho servem para medir o desenvolvimento da força humana de trabalho e, além disso, indicam as condições sociais em que se realiza o trabalho". (MARX, 2010, p. 214). 
Ao ler Marx (2010) pode-se verificar que o trabalho possui um duplo caráter: o trabalho concreto e o trabalho abstrato. O trabalho concreto está relacionado ao seu valor de uso e caracterizado pelo modo operatório da atividade realizada pelo homem na natureza, diferenciando-se de uma atividade profissional para outra. Já o trabalho abstrato está relacionado ao valor-de-troca da força de trabalho e é o mecanismo utilizado para permitir a comparação entre os diferentes trabalhos concretos realizados pelos trabalhadores, igualando os diferentes tipos de atividades a um denominador comum.

Todo trabalho é, de um lado, dispêndio de força de trabalho, no sentido fisiológico, e, nessa qualidade de trabalho humano igual ou abstrato, cria o valor das mercadorias. Todo trabalho, por outro lado, é dispêndio de força humana de trabalho, sob forma especial, para um determinado fim, e, nessa qualidade de trabalho útil e concreto, produz valores-de-uso. (MARX, 2010, p. 68).

E ainda mais:

Um valor-de-uso ou um bem só possui, portanto, valor, porque nele está corporificado, materializado, trabalho humano abstrato. Como medir a grandeza do seu valor? Por meio da quantidade da "substância criadora de valor" nele contida, o trabalho". A quantidade de trabalho, por sua vez, medese pelo tempo de sua duração, e o tempo de trabalho, por frações do tempo, como hora, dia etc. (MARX, 2010, p. 60).

No processo de troca, as mercadorias são abstraídas e comparadas pelo dispêndio da força de trabalho utilizada em cada mercadoria. O tempo de trabalho é a variável utilizada para comparar e balizar o processo de troca. Deste modo, o trabalho abstrato foi uma estratégia idealizada por Marx para avançar na teoria do valor clássica, (proposta pelos economistas David Ricardo e Adam Smith) e criar a teoria do valor trabalho, na qual o valor da mercadoria é igual ao tempo de trabalho socialmente necessário. Isto nos permite a comparação entre diferentes tipos de trabalho, realizado por diferentes trabalhadores, a partir do uso de instrumentos de trabalhos diferentes.

No processo de ação do homem sobre o objeto, o objeto fica sujeito à subordinação do homem. "Ele não transforma apenas o material sobre o qual opera; ele imprime ao material o projeto que tinha conscientemente em mira, o qual constitui a lei determinante do seu modo de operar e ao qual tem de subordinar sua vontade. (MARX, 2010, p. 212)".

Para Marx (2010) os elementos que compõem o processo de trabalho podem ser simplificados em:

1) A atividade orientada para um fim;

2) O objeto; 
3) Os meios de trabalho

A atividade orientada a um fim pode ser entendida como o trabalho realizado pelo próprio homem. Ele é central no processo de transformação e deve ser a categoria mais importante deste processo.

O objeto (matérias-primas, informações etc.) encontrado na natureza irá sofrer o processo de transformação para se transformarem em respectivas mercadorias. Os meios de trabalho são os complexos de máquinas, equipamentos e ferramentas que os trabalhadores colocam entre si e o objeto de trabalho.

Ao contrário da visão de muitos teóricos liberais, que valorizam a importância das empresas para a sociedade, e os trabalhadores são meros insumos (recursos produtivos) de transformação - na abordagem de Marx sobre o processo de trabalho a força de trabalho é a categorial central do processo de transformação.

Dentro do ponto vista marxista conforme, o trabalho não é algo ex-ante, mas aquele que faz funcionar todo o sistema e vai produzir todo o trabalho necessário e todo trabalho excedente. Ela é a categoria que consegue produzir outras mercadorias com maior valor agregado.

No processo de trabalho, quando os meios de trabalho entram em contato com os trabalhadores há um processo de materialização da força de trabalho. Nele, o homem objetiva uma ação junto à matéria para obter um fim desejado. "Põe em movimento as forças naturais de seu corpo - braços e pernas, cabeça e mãos -, a fim de apropriar-se dos recursos da natureza, imprimindo-lhes forma útil à vida humana.” (MARX, 2010, p. 211).

Os produtos gerados por um determinado trabalhador (e não por uma determinada organização - como defendem alguns autores da administração da produção) possuem um valor de uso que pode ser utilizado como meios de subsistência ou meios de produção (quando utilizados para gerar outros produtos). Ao entrar em um processo de produção, os produtos perdem o caráter de produtos e se transformam em meios de produção e de alguma forma perdem seu vínculo com quem o produziu anteriormente.

O processo de trabalho é caracterizado pela presença de dois elementos interligados que se destacam: a prévia ideação e a objetivação. Na prévia-ideação, as consequências da ação são previstas e processadas no cérebro do trabalhador, de forma que o objetivo é idealizado antes e durante a realização na prática. "Ao ser levada à prática, a prévia-ideação se materializa num objeto, se objetiva” (LESSA, 1996, p. 25) o processo de transformação é chamado de objetivação. Pela objetivação "uma posição teleológica se realiza no âmbito do ser material como nascimento de uma nova objetividade” (LUKÁCS apud LESSA, 1996, p. 25). 
Como pode ser verificado, o trabalho é uma atividade que se concretiza com uma ação. Marx já tinha observado isto ao afirmar que o trabalho só é realmente entendido se for analisado na atividade ou na ação. É na ação que os trabalhadores se deparam com os erros e os acertos da realização de uma determinada operação ou como nos diz Marx (2010, p.211) “a utilização da força de trabalho é o próprio trabalho".

Não se pode entender o processo de trabalho como algo isolado, resultado daquele trabalhador e naquele espaço específico. O processo de trabalho é algo mais complexo, resultado de um encadeamento de operações realizadas por diversos trabalhadores, que desenvolveram ou criaram meios de produção que estão sendo utilizados em um determinado espaço de produção.

Quando um valor-de-uso sai do processo de trabalho como produto, participaram da sua feitura, como meios de produção, outros valores-de-uso, produtos de anteriores processos de trabalho. Valor-de-uso que é produto de um trabalho torna-se assim meio de produção de outro. Os produtos destinados a servir de meio de produção não são apenas resultado, mas também condição do processo de trabalho. (MARX, 2010, p. 215).

Assim, ao olhar uma determinada atividade de trabalho, é preciso ter em mente que é "um objeto já filtrado pelo trabalho, um produto do próprio trabalho... produto de uma transformação continuada, através de muitas gerações, realizada sob controle do homem e pelo seu trabalho.” (MARX, 2010, p. 215).

Todo trabalho está situado em um contexto econômico e social. Para se valer como trabalho é necessário uma utilidade econômica do esforço desprendido na realização da atividade. Isto é o que Marx chama de valor de uso. É o valor de uso que vai fazer uma mercadoria ser atrativa para o consumo. Uma mercadoria só poderá ser comercializada se possuir uma utilidade. E o trabalho só é útil se produzir mercadorias que possuam valor de uso.

\section{CONSIDERAÇÕES FINAIS}

Em uma sociedade capitalista, o trabalho é levado para o contexto de uma mercadoria, onde o trabalhador vende a sua força de trabalho para sobreviver. Para entender o trabalho na atualidade é necessário entender a lógica do modo de produção capitalista que está fundamentado no ganho de lucro. Sua lógica de funcionamento está no processo de transformar D (dinheiro) em um D' (dinheiro em acréscimo - mais dinheiro) e ele faz isto por meio da compra de uma mercadoria específica (M) que é capaz de transformar o D em D'. Assim, o processo de valorização do capital está baseado na lógica de transformação D - M - D'. Ou seja, dinheiro (D) 
que é transformado em mercadoria $(M)$ e que no processo de venda, retorna para a empresa em forma de dinheiro valorizado (D').

No capitalismo a única mercadoria capaz de transforma o $\mathrm{D}$ em D’ é a força de trabalho. A força de trabalho é a única mercadoria que tem a especificidade de produzir um valor maior do que ela própria vale. Assim, ao final de uma jornada de trabalho a força de trabalho (comprada pelo capitalista) produz outra mercadoria cujo valor é suficiente para pagar o valor da força de trabalho e a geração de lucro.

O trabalho é a categoria central do capitalismo, pois no intercâmbio do homem com a natureza é capaz de produzir novas necessidades e possibilidades. É no ato de realização do trabalho que a força de trabalho cria o mais valor, que no campo da economia política é chamada de mais-valia.

\section{REFERÊNCIAS}

ENGELS, F. Sobre o papel do trabalho na transformação do macaco em homem. In: Antunes. R. (org.) A dialética do trabalho: Escritos de Marx e Engels. São Paulo: Expressão Popular, 2004. p. 11-28.

LESSA, S. A Ontologia de Lukács. Maceió: EDUFAL, 1996. 146 p.

LUKÁCS, G. O trabalho. In: Ontologia do Ser Social. Tradução de Ivo Tonet. Mimeo, 1981.

MARX, K. O Capital: critica da economia política. Livro 01, Vol. 01. 27. ed. Rio de Janeiro: Civilização Brasileira, 2010. 